\title{
DIVERGÊNCIA GENÉTICA EM FEIJÃO PRETO
}

\author{
GENETIC DIVERGENCE IN BLACK BEAN
}

\author{
Jefferson Luís Meirelles Coimbra ${ }^{1}$ Fernando Irajá Felix de Carvalho ${ }^{2}$ \\ Silmar Hemp ${ }^{3}$ Antônio Costa de Oliveira ${ }^{2}$ Simone Alves da Silva ${ }^{4}$
}

\section{RESUMO}

\begin{abstract}
Vinte genótipos de feijão (Phaseolus vulgaris L.) foram avaliados, no município de Lages/SC; quatro caracteres de importância agronômica sobre a divergência genética em feijão. Esta estimativa foi realizada através da estatística de Mahalanobis e, para o agrupamento dos genótipos mais similares, o método de Tocher. $O$ experimento, em blocos ao acaso com três repetições e três épocas de semeadura por tratamento, foi conduzido no período de safra e safrinha no ano agrícola de 1996/97. Os caracteres agronômicos avaliados foram: número de dias entre a emergência e o florescimento (EMFL), número de dias entre a emergência e a maturação de colheita (EMMC), peso de mil grãos (PMG) e o rendimento de grãos por unidade de área. Os resultados obtidos no presente estudo permitiram caracterizar possíveis genótipos para serem utilizados em cruzamentos dirigidos. $O$ estudo dos vinte genótipos evidenciou um alto grau de divergência genética e apontou os caracteres agronômicos EMFL e PMG com maior contribuição relativa para a divergência genética, indicando que estes dois caracteres devem ser priorizados em programas de melhoramento de feijão.
\end{abstract}

Palavras-chave: Phaseolus vulgaris $L ., D^{2}$ e Tocher, divergência morfológica.

\section{SUMMARY}

Twenty bean genotypes (Phaseolus vulgaris L.) were evaluated, in the county of Lages/SC, Brazil for the influence of three traits of agronomic importance on the genetic divergence in beans. This estimate was accomplished through the statistics of Mahalanobis and, for grouping the most similar genotypes, the method of Tocher. The experiment was performed with a randomized block design, with three replications and three sowing dates in both crop and out of season periods in the agricultural year of 1996/97. The analyzed agronomic traits were: number of days between emergency and flowering (EMFL), number of days between emergency and harvesting point $(E M M C)$, weight of a thousand grains (PMG), and the yield of grains per unit of area. The results obtained allowed to identify possible genotypes to be used in driven crossings. The study of the twenty bean genotypes showed a high degree of genetic divergence and indicated the agronomic characters EMFL and $P M G$ as larger contributions to the genetic divergence, indicating, that these two characters should be prioritized in programs of bean improvement.

Key words: Phaseolus vulgaris $L ., D^{2}$ and Tocher, morphological diversity.

\section{INTRODUÇÃO}

O feijão (Phaseolus vulgaris L.) foi introduzido da América Central; RAMALHO (1993) comenta que, provavelmente, sua vinda tenha ocorrido em pelo menos duas rotas distintas, América Central e Sul dos Andes, tendo como características marcantes o tamanho de grãos pequenos (25g/ 100 sementes) e grandes (125g/100sementes). Com o passar do tempo, foram surgindo novos cultivares, seja por introdução, hibridação artificial, seleção natural e artificial ou mutações, mas principalmente pelo uso contínuo de sementes ano após ano pelos agricultores. Atualmente, o grande número de genótipos existentes, possivelmente, tenha por base a introdução de um mesmo genótipo em diversos locais, sem que a identificação original tenha sido mantida. Essas introduções geralmente recebem nomes próprios do local de cultivo, como por exemplo o genótipo IAPAR 31, tipo de grão carioca que é popularmente chamado de "cara suja" por alguns agricultores do Planalto Catarinense.

Medidas de similaridade genética, como forma de caracterizar e identificar os diversos genótipos distintos das principais espécies, têm despertado o interesse de vários autores (CARVALHO et al. 1972; DAHER et al. 1997a.; DAHER et al. 1997b;

\footnotetext{
${ }^{1}$ Engenheiro Agrônomo, aluno do Curso de Pós-graduação da UFPel. Pelotas, RS. Bolsista da CAPES. e-mail: jlmcpos@ufpel.tche.br

${ }^{2}$ Engenheiro Agrônomo, PhD., Professor da UFPel. Pesquisador do CNPq. CP 354, 96001-970. Capão do Leão, RS.

${ }^{3}$ Engenheiro Agrônomo, Mestre, Pesquisador da EPAGRI. CTA do Oeste.

${ }^{4}$ Engenheiro Agrônomo, aluno do Curso de Pós-graduação da UFPel.
} 
SANTOS et al. 1997; GAUR et al. 1978; CASLER, 1995).

A polinização dirigida é de suma importância em todas as espécies vegetais, porém no caso do feijoeiro esta técnica é trabalhosa e bastante meticulosa, limitando, muitas vezes, o sucesso no programa de melhoramento genético. Sendo assim, modelos biométricos que estimam a divergência morfológica entre caracteres de importância agronômica são importantes no estudo e na discriminação de genótipos em diversas espécies vegetais, evidenciando um potencial na avaliação da similaridade entre genótipos.

BORÉM (1997) comenta que, para poder ser utilizada a divergência genética disponível nos bancos de germoplasma, é necessário que os genótipos sejam caracterizados e documentados de forma que o melhoramento possa identificar a potencialidade de uso destas constituições genéticas no progresso do feijão.

Segundo GAUR et al. (1978), a análise multivariada $\left(\mathrm{D}^{2}\right)$ pode ser empregada como uma poderosa ferramenta para estimar a divergência genética com o intuito de auxiliar na escolha de combinações mais promissoras. O Ensaio Sulbrasileiro de Feijão Preto (ESB) possui um número muito grande de genótipos, necessitando uma seleção entre os genótipos mais promissores em possíveis cruzamentos artificiais para progresso no melhoramento genético da cultura.

O presente estudo teve como objetivo principal caracterizar morfologicamente a divergência genética e promover seu agrupamento.

\section{MATERIAL E MÉTODOS}

Os experimentos foram conduzidos durante o ano agrícola de 1996/97 no município de Chapecó/SC, situado no oeste catarinense, cujo solo pertence à unidade de mapeamento Ciríaco (WILDNER, 1992).

O preparo do solo foi realizado de forma convencional segundo indicações técnicas relatadas por WILDNER (1992). As adubações na base e cobertura utilizadas foram de 15,55 e $60 \mathrm{~kg} / \mathrm{ha}$ de NPK e $70 \mathrm{~kg} / \mathrm{ha}$ de $\mathrm{N}$, respectivamente, seguindo as recomendações descritas pelos autores BALDISSERA \& SCHERER (1992). O controle de plantas invasoras foi efetuado com aplicação de $2 \mathrm{~kg} / \mathrm{ha}$ de Metachlor, sendo posteriormente realizada capina manual para eli-

"/ padrões minação de possíveis invasoras remanescentes. Para o controle de pragas, foi empregado o inseticida Methamidophos (Tamaron BR), na dose de 0,5 a 1,0 1/ha do produto comercial. O controle foi realizado sempre que necessário.

Os genótipos de feijão preto incluídos neste ensaio foram em número de 20 , sendo 17 linhagens e três cultivares utilizados como padrões (tabela 1). $\mathrm{O}$ experimento teve um delineamento experimental em blocos ao acaso, com três repetições, em três épocas de semeadura. Cada unidade experimental foi composta por duas fileiras de $5 \mathrm{~m}$ de comprimento com 10 plantas/m linear ou 200.000 plantas/ha, com espaçamento de $0,5 \mathrm{~m}$ entre fileiras e $0,2 \mathrm{~m}$ entre covas dentro das fileiras. A área útil foi formada por duas fileiras, compreendendo $4 \mathrm{~m}^{2}$. O local, das três épocas, nos dois anos, recebeu manejo similar em todas os experimentos avaliados.

As semeaduras foram realizadas no ambiente $A_{1}$ em 03/10/1995 no período preferencial para a cultura naquela região e, no ambiente $\mathrm{A}_{2} \mathrm{em}$ 08/02/1996 (HEMP et al. 1994).

As variáveis avaliadas foram: número de dias entre a emergência e o florescimento (EMFL), número de dias entre a emergência e a maturação de colheita (EMMC), peso de mil grãos (PMG) e rendimento de grãos à 13\% de umidade. Essas avalia-

Tabela 1 - Caracteres agronômicos, emergência ao florescimento (EMFL, dias), emergência a maturação de colheita (EMMC, dias), peso de mil grãos (PMG, g) e rendimento de grãos $(\mathrm{kg} / \mathrm{ha})$ à $13 \%$ de umidade em 20 genótipos em dois ambientes $\left(\mathrm{A}_{1} \mathrm{e} \mathrm{A}_{2}\right)$. Chapecó/SC.

\begin{tabular}{cccccr}
\hline Ordem & Genótipos & EMFL & EMMC & PMG & Rendimento \\
& & & & & \\
\hline & & & & & \\
1 & AN 910390 & 35,0 & 79,0 & 177,0 & 1055,00 \\
2 & AN 911104 & 38,7 & 80,0 & 134,7 & 911,67 \\
3 & AN 911120 & 37,3 & 79,7 & 138,7 & 890,67 \\
4 & Barriga Verde & 35,0 & 81,7 & 169,0 & 1099,33 \\
5 & CB 733783 & 36,0 & 79,3 & 157,7 & 1330,67 \\
6 & LA 9016742 & 36,7 & 78,3 & 131,7 & 753,00 \\
7 & LP 90-94 & 35,7 & 80,7 & 162,7 & 945,33 \\
8 & LP 93-80 & 37,0 & 79,3 & 167,0 & 742,67 \\
9 & LP 94-62 & 36,3 & 78,3 & 123,7 & 1167,33 \\
10 & LP 94-96 & 38,0 & 81,7 & 162,7 & 903,33 \\
11 & LR 9115398 & 35,0 & 82,0 & 178,0 & 1272,00 \\
12 & MA 733327 & 37,0 & 79,7 & 159,0 & 1127,67 \\
13 & Macanudo & 33,7 & 77,0 & 147,0 & 1133,67 \\
14 & Palmitos ${ }^{*}$ & 34,7 & 76,3 & 153,7 & 880,00 \\
15 & TB 94-01 & 35,3 & 78,7 & 188,3 & 997,67 \\
16 & TB 94-08 & 33,7 & 76,3 & 177,0 & 1117,00 \\
17 & TB 94-12 & 33,3 & 79,7 & 134,0 & 913,67 \\
18 & TB 94-14 & 36,3 & 82,0 & 133,7 & 981,00 \\
19 & TB 94-15 & 34,7 & 78,3 & 157,3 & 978,33 \\
20 & TB 94-20 & 37,3 & 80,3 & 159,0 & 667,00 \\
& & & & & \\
\hline
\end{tabular}

Ciência Rural, v. 29, n. 3, 1999. 
ções foram baseadas nos estádios de crescimento da cultura, segundo a escala proposta pelo CIAT, (1991). A emergência foi avaliada no estádio $V_{1}$, a data de floração no estádio $\mathrm{R}_{6}$ e a data de maturação de colheita no estádio $\mathrm{R}_{9}$, quando $50 \%$ dos legumes da parcela estavam aparentemente em maturação fisiológica.

As medidas de similaridade com bases em variáveis quantitativas foram determinadas segundo o modelo de análise multivariada. A divergência genética foi estimada usando a estatística de Mahalanobis $\left(D^{2}\right)$ e, para agrupamento dos genótipos, foi empregado o método de Tocher, descrito por CRUZ \& REGAZZI (1997). As análises foram realizadas, separadamente para cada ambiente, usando o programa computacional Genes, desenvolvido pela Universidade Federal de Viçosa (CRUZ, 1997).

\section{RESULTADOS E DISCUSSÃO}

A análise de variância evidenciou diferenças significativas nos genótipos para todos os caracteres agronômicos estudados. Foram calculados os valores de $\mathrm{D}^{2}$ (192 combinações possíveis) correspondendo aos pares de comparações de 20 genótipos avaliados.

As médias dos caracteres analisados estão na tabela 1. Estas médias, além de fornecerem uma caracterização do genótipo utilizado, são indispensáveis para o cálculo das estatísticas que serão descritas a seguir.

Na tabela, 2 estão apresentados os grupos similares de genótipos de feijão preto avaliados em dois ambientes. A formação de quatro e sete grupos nos ambientes $\mathrm{A}_{1}$ e $\mathrm{A}_{2}$, respectivamente, foi observada. Nos dois ambientes, o grupo 1 evidenciou o

Tabela 2 - Grupo similares dos vinte genótipos de feijão preto avaliados em dois ambientes $\left(\mathrm{A}_{1}\right.$ e $\left.\mathrm{A}_{2}\right)$ distintos, agrupados pelo método Tocher. Chapecó, SC.

\begin{tabular}{|c|c|c|c|c|}
\hline \multirow[b]{2}{*}{ Grupo } & \multicolumn{2}{|r|}{ Ambiente $\mathrm{A}_{1}$} & \multicolumn{2}{|c|}{ Ambiente $\mathrm{A}_{2}$} \\
\hline & N.G* & Agrupamento & N.G & Agrupamento \\
\hline 1 & 10 & $8-15-1-16-11-13-4-14-19-5$ & 5 & $14-19-7-4-12$ \\
\hline 2 & 8 & $12-18-7-20-6-2-3-17$ & 4 & $2-3-18-6$ \\
\hline 3 & 1 & 9 & 3 & $8-20-10$ \\
\hline 4 & 1 & 10 & 4 & $1-16-11-15$ \\
\hline 5 & $\mathrm{x}$ & $\mathrm{x}$ & 2 & $13-17$ \\
\hline 6 & $\mathrm{x}$ & $\mathrm{x}$ & 1 & 9 \\
\hline 7 & $\mathrm{x}$ & $\mathrm{x}$ & 1 & 5 \\
\hline
\end{tabular}

* N.G - número total de genótipos maior número de genótipos. Na comparação por ambiente, o grupo 1 apontou o dobro do número total de genótipos (10) agrupados no $\mathrm{A}_{1}$. $\mathrm{O}$ número de genótipos, comparativamente de cada grupo, não foi igual nos dois ambientes, exceto para os grupos (3 e 6), que apresentaram sempre o mesmo genótipo (tabela 2). Por outro lado, no $\mathrm{A}_{1}$, pode ser verificado que os três cultivares padrões $(4,13$ e 14) estão inseridos no grupo 1. Já para o ambiente $\mathrm{A}_{2}$, apenas os genótipos 4 e 14 pertencem ao mesmo grupo; enquanto que o genótipo 13 está inserido no agrupamento 5. A alteração do número e do genótipo constituinte dos grupos de um ambiente para outro pode ser explicada com base na expressão do gene que, dependendo das condições ambientais, pode ser diferente. Um caráter medido em dois ambientes, para FALCONER (1987), não deve ser visto como único, e sim como dois caracteres.

Na tabela 3, estão apresentadas as estimativas das 20 maiores e menores distâncias estabelecidas pelo método aglomerativo, tendo como medida de dissimilaridade a estatística de Mahalanobis $\left(\mathrm{D}^{2}\right)$ em dois ambientes distintos. No geral, as maiores $\mathrm{D}^{2}$ ocorreram no $A_{1}$. Porém, os pares $(6 \times 1)$ e $(15 \times 9)$ apresentaram valores aproximados em cada ambiente. A magnitude nas distâncias foi mais elevada no $\mathrm{A}_{1}$, comparativamente com a $\mathrm{A}_{2}$. Esta grandeza na soma das estimativa do $A_{1}$ foi $52 \%$ superior ao $A_{2}$, evidenciando a maior expressão dos caracteres avaliados no ambiente $\mathrm{A}_{1}$. Neste ambiente, os genótipos provavelmente não tenham sofrido estresse hídrico que, normalmente, ocorre em semeaduras fora da época recomendada pela pesquisa. No ambiente $A_{1}$, a maior e menor estimativa de $\mathrm{D}^{2}$ foram observadas entre o par de genótipos 1x9 e 14x19, respectivamente. Segundo GAUR et al. (1978), a magnitude da divergência genética está intimamente relacionada com o grau de heterose encontrada na espécie em estudo.

$\mathrm{Na}$ tabela 4, está apresentado o número de genótipos coincidentes entre os agrupamentos estabelecidos pelo método de Tocher, nos dois ambientes avaliados. Se a correlação genética for alta, o desempenho de um caráter em um ambiente será representado, aproximadamente, pelo mesmo grupo de gene e, se a correlação for baixa, os caracteres serão muito diferentes e exigirão um grupo diferente de genes (FALCONER, 1987). Pode ser observado (tabela 4) que os grupos 1,2 e 4 revelaram o maior número de genótipos com divergência estável. É desejável que a expressão da divergência genética entre genótipos se mantenha estável ou consistente nos ambientes avaliados para que 
Tabela 3 - Estimativas das vinte maiores e menores distâncias e seus respectivos pares de genótipos, estabelecidas pela estatística de Mahala-

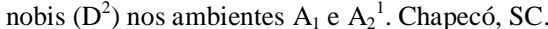

\begin{tabular}{|c|c|c|c|c|c|c|c|}
\hline \multicolumn{4}{|c|}{$\mathrm{A}_{1}$} & \multicolumn{4}{|c|}{$\mathrm{A}_{2}$} \\
\hline \multicolumn{2}{|c|}{$>\mathrm{D}^{2}$} & \multicolumn{2}{|c|}{$<\mathrm{D}^{2}$} & \multicolumn{2}{|c|}{$>\mathrm{D}^{2}$} & \multicolumn{2}{|c|}{$<\mathrm{D}^{2}$} \\
\hline Distância & Genótipos & Distância & Genótipos & Distância & Genótipos & Distância & Genótipos \\
\hline 232,45 & $1-9$ & 6,40 & $1-15$ & 81,53 & $1-9$ & 3,00 & $1-4$ \\
\hline 134,08 & $2-1$ & 3,42 & $2-3$ & 85,24 & $2-15$ & 1,94 & $2-3$ \\
\hline 101,32 & $3-1$ & 3,42 & $3-2$ & 69,60 & $3-15$ & 1,94 & $3-2$ \\
\hline 109,28 & $4-9$ & 3,59 & $4-19$ & 59,77 & $4-9$ & 2,52 & $4-7$ \\
\hline 80,12 & $5-10$ & 5,57 & $5-19$ & 35,45 & $5-15$ & 3,70 & $5-12$ \\
\hline 126,14 & $6-1$ & 7,23 & $6-2$ & 89,64 & $6-15$ & 3,16 & $6-3$ \\
\hline 84,20 & $7-1$ & 3,98 & $7-12$ & 48,62 & $7-9$ & 2,52 & $7-4$ \\
\hline 165,40 & $8-9$ & 1,70 & $8-15$ & 70,48 & $8-9$ & 2,29 & $8-20$ \\
\hline 232,45 & $9-1$ & 17,98 & $9-2$ & 120,93 & $9-15$ & 8,14 & $9-18$ \\
\hline 180,90 & $10-9$ & 29,11 & $10-7$ & 57,86 & $10-9$ & 3,99 & $10-8$ \\
\hline 220,83 & $11-9$ & 7,64 & $11-8$ & 82,75 & $11-9$ & 3,71 & $11-4$ \\
\hline 90,86 & $12-1$ & 2,52 & $12-18$ & 37,28 & $12-9$ & 3,70 & $12-5$ \\
\hline 156,08 & $13-9$ & 7,32 & $13-4$ & 56,47 & $13-15$ & 6,51 & $13-14$ \\
\hline 87,59 & $14-9$ & 11,70 & $14-5$ & 35,86 & $14-15$ & 1,37 & $14-19$ \\
\hline 166,10 & $15-9$ & 1,70 & $15-8$ & 120,93 & $15-9$ & 4,16 & $15-1$ \\
\hline 175,81 & $16-9$ & 4,93 & $16-15$ & 83,76 & $16-9$ & 3,71 & $16-1$ \\
\hline 167,32 & $17-1$ & 9,79 & $17-18$ & 89,01 & $17-15$ & 8,62 & $17-13$ \\
\hline 114,04 & $18-1$ & 2,52 & $18-12$ & 85,11 & $18-15$ & 2,56 & $18-3$ \\
\hline 84,30 & $19-9$ & 3,59 & $19-4$ & 36,20 & $19-9$ & 1,37 & $19-14$ \\
\hline 87,49 & $20-1$ & 6,13 & $20-18$ & 58,84 & $20-9$ & 2,29 & $20-8$ \\
\hline \multicolumn{3}{|c|}{ Soma das estimativas $\mathrm{de}^{2 /} \mathrm{D}^{2}$} & 9705,95 & & & & 5052,81 \\
\hline
\end{tabular}

$\mathrm{A}_{1}$ - safra; $\mathrm{A}_{2}$ - safrinha.

${ }^{2}$ refere-se ao total das estimativas das $\mathrm{D}^{2}$ para os 20 genótipos.

possa ser utilizada no melhoramento genético vegetal (JAIN et al. 1981). Os genótipos que se mantiveram distantes, não fazendo parte de um mesmo grupo em ambos os ambientes, podem ter expressado

Tabela 4 - Número de genótipos coincidentes entre os agrupamentos, estabelecidos pelo método de Tocher, nos dois ambientes avaliados $\left(\mathrm{A}_{1}\right.$ e $\left.\mathrm{A}_{2}\right)$. Chapecó, SC.

Ambiente 2

\begin{tabular}{ccccccccc}
\cline { 3 - 6 } Ambiente 1 & I & II & III & IV & V & VI & VII & Total \\
& & & & & & & & \\
\hline I & 3 & 1 & 0 & 4 & 1 & 0 & 1 & 10 \\
II & 2 & 4 & 1 & 0 & 1 & 0 & 0 & 8 \\
III & 0 & 0 & 0 & 0 & 0 & 1 & 0 & 1 \\
IV & 0 & 0 & 1 & 0 & 0 & 0 & 0 & 1 \\
& & & & & & & & \\
\hline & & 5 & 2 & 4 & 2 & 1 & 1 & 20 \\
\hline
\end{tabular}

sua real divergência genética, podendo ser considerados como promissores nas hibridações artificiais, com a finalidade de incrementar a variabilidade genética entre os caracteres agronômicos aqui estudados. Portanto, as seguintes combinações 19x2, 19x3 e 19x18 são promissoras (tabela 2).

A contribuição relativa dos caracteres para a divergência genética dos 20 genótipos de feijão preto nos dois ambientes está descrita na tabela 5. Pode ser observado que, nesta tabela, os caracteres não tiveram a mesma estimativa da contribuição relativa e nem a ordem de classificação para contribuição da divergência genética nos dois ambientes. Neste aspecto, é necessário salientar que caracteres com herança qualitativa são bons marcadores genéticos, porque são pouco influenciados pelo ambiente e, possivelmente, controlados por poucos genes (RAMALHO et al., 1993). Os caracteres peso de mil grãos e ciclo vegetativo da cultura evidenciaram uma estimativa da contribuição relativa para a 
Tabela 5 - Contribuição relativa dos quatro caracteres agronômicos avaliados para a divergência genética em 20 genótipos de feijão preto avaliados em dois ambientes distintos $\mathrm{A}_{1}$ e $\mathrm{A} 2$, no município de Chapecó/SC no ano agrícola de 1996/97.

\begin{tabular}{lrr}
\hline Variável & $\mathrm{A}_{1}(\%)$ & $\mathrm{A}_{2}(\%)$ \\
\hline & & \\
EMFL & 18,87 & 14,15 \\
EMMC & 8,48 & 4,29 \\
PMG & 68,15 & 68,40 \\
Rendimento de grãos & 4,50 & 13,16 \\
& & \\
\hline
\end{tabular}

divergência relativamente elevada e de valores próximos entre os dois ambientes avaliados $87,02 \%$ e $82,55 \%$, respectivamente em $\mathrm{A}_{1}$ e $\mathrm{A}_{2}$, podendo ser priorizado nos estudos de divergência genética do feijão preto.

\section{CONCLUSÃO}

De um total de 20 genótipos de feijão avaliados em dois ambientes, foi constatado um alto grau de divergência genética, onde ciclo vegetativo e peso de mil grãos foram os caracteres agronômicos que mais contribuíram relativamente para a divergência genética.

\section{REFERÊNCIAS BIBLIOGRÁFICAS}

BALDISSERA, I.T., SCHERER, E.E. Correção da acidez do solo e adubação da cultura do feijão. In: EPAGRI. A cultura do feijão em Santa Catarina. Florianópolis: EPAGRI, 1992. p. $115-136,285 \mathrm{p}$

BORÉM, A. Melhoramento de Plantas. Viçosa: UFV, 1997. 547 p.

CARVALHO, M.M., MOZER, O.L., SILVA, J.B., $\boldsymbol{e} \boldsymbol{t} \boldsymbol{a l}$. Identificação de variedades e híbridos de capim-elefante (Pennisetum purpureum Schum). In: REUNIÃO ANUAL DA SOCIEDADE BRASILEIRA DE ZOOTECNIA. Anais.. Viçosa: SBZ, 1972, p. 209-210.

CASLER, M.D. Patterns of variation in a collection of Perennial
Ryegraas Acessions. Crop Sciences, Madison, v. 35, n. 5, p. 1169-1177, 1995.

CENTRO INTERNACIONAL DE AGRICULTURA TROPICAL. Sistema estándar para la evaluación de germoplasma de frijol. 2. ed. Cali, Colômbia: CIAT, 1991. $56 \mathrm{p}$.

CRUZ, C.D., REGAZZI, A.J. Modelos biométricos aplicados ao melhoramento genético. 2. ed. Viçosa: UFV, 1997. 390 p.

CRUZ, C.D. Aplicativo computacional em genética e estatística. Viçosa: UFV, 1997. 442 p.

DAHER, R.F., MORAES, C.F., CRUZ, C.D., et al. Diversidade morfológica e isoezimática em capim-elefante (Pennisetum purpureum Schum). Revista Brasileira de Zootecnia, Viçosa, v. 6, n. 2, p. 255-264, 1997.

DAHER, R.F., MORAES, C.F., CRUZ, C.D., et al. Seleção morfológica discriminantes em capim-elefante (Pennisetum purpureum Schum). Revista Brasileira de Zootecnia, Viçosa, v. 6, n. 2, p. 247-254, 1997.

FALCONER, D.S. Introdução à genética quantitativa. Viçosa: Imprensa Universitária, 1987. 279 p.

GAUR, P.C., GUPTA, P.K., KISHORE, H. Studies on genetic divergence in potato. Euphytica, Wageningen, v. 27, p. 316$368,1978$.

HEMP, S., MASSIGNAM, A.M., GANDIM, C.L., et al. Feijão. In: EPAGRI. Recomendações de cultivares para o Estado de Santa Catarina 1993/1994. Florianópolis: EPAGRI, 1994. p. 55-61. Boletim técnico, 67.

JAIN, K.C., PANDYA, B.P., PANDE, K. Genetic divergence in chickpea. Indian Journal of genetics \& Plant Breeding. New Delhi, v. 41, n. 2, p. 220-225, 1981.

RAMALHO, M.A.P., SANTOS, J.B., ZIMMERMANN, M, J de $O$. Genética quantitativa em plantas autógamas. Aplicações ao melhoramento do feijoeiro. Goiânia: UFG, 1993. 271p.

SANTOS, C.F., MENEZES, E.A., ARAÚJO, F.P. Divergência genética em genótipos de feijão-de-corda avaliados em dois ambientes. Revista Ceres, Viçosa, v. 44, n. 251, p. 35-42, 1997.

WILDNER, L.P. Manejo do solo para cultura do feijão: Principais características e recomendações técnicas. In: EPAGRI. A cultura do feijão em Santa Catarina. Florianópolis: EPAGRI, 1992. p. 83-114. 